\title{
IPad Apps’ Influence on Students' Compliance
}

\author{
Huda A. Almumen ${ }^{1, *}$ \\ ${ }^{1}$ Learning and Instruction Department, State University of New York at Buffalo, USA \\ *Correspondence: Learning and Instruction Department, State University of New York at \\ Buffalo, 120 Autumn Creek, Apt. J, East Amherst, 14051 NY, USA. Tel: 1-716-704-9293 \\ E-mail: hudaaama@buffalo.edu
}

Received: March 13, 2015 Accepted: March 30, 2015 Published: April 10, 2015

doi:10.5296/ije.v7i2.7235 URL: http://dx.doi.org/10.5296/ije.v7i2.7235

\begin{abstract}
The emergence of technology has ameliorated various fields in education. Technological applications are being adopted by several schools to facilitate students' learning. Teachers are using such products to pave the way for more effective teaching practices. In addition, these technological applications are utilized by parents to increase their children's positive behaviors. IPad and its educational application programs are effective tools for increasing elementary students' compliance with doing the reading homework. One of these applications is Book Creator in which individuals can create children's interactive stories. These interactive stories make the reading homework an interesting assignment, and therefore students' compliance with doing homework is likely increasing. This paper describes the importance of compliance with reading homework for students whose English is their second language. In addition, this paper discusses how interactive reading books promote compliance with homework completion. The study was conducted using a single subject withdrawal design.
\end{abstract}

Keywords: reading homework, iPad, compliance, technology, single subject 
Homework completion is one of the essential aspects in reinforcing students' learning, especially, if the homework is a reading assignment. When children engage in reading, they are more likely to experience academic success. Evidence of their learning acquisition can be demonstrated through their reading (Justice \& Sofka, 2010). Wanzek, Al Otaiba and Petscher (2014) claimed one of the basic reasons for being at risk of failure and dropping out of high school is students' shortage of successful reading skills. Accordingly, reading plays a major role in the success or failure in children's academic performance which will affect later on their career lives.

In addition to good reading instruction during the school day, reinforcement of reading skills must occur outside of the school environment. Amelioration of students' reading deficiencies includes compliance of reading homework assigned by teachers. Reading homework completion is essential, specifically for those who are struggling in reading. The acceleration of students' reading completion can be achieved by scaffolding. Justice and Sofka (2010) defined scaffolding as an instructional method used by a parent, a teacher or even a peer who is more knowledgeable than the student to pave the way for more efficient reading. Scaffolding can be represented in various ways such as parents' assistance in a reading activity or a peer's explanation for a specific reading task. Parents' role in homework completion is demonstrated in their encouragement and help to their child in reading activities. According to Buyuktaskapu (2012), family support plays a pivotal role in developing a child's reading skills. By their help, parents convey a message that reading is a fundamental skill not only related to school activity, but also to our daily life experiences (Buyuktaskapu). Therefore, knowing such importance promotes students' compliance with reading homework. Significance of reading is demonstrated in realizing its purpose. Kucer (2014) indicated any type of reading has a purpose derived from the environmental context around learners. In this context both reader and the text are interacting and operating with each other. The association of reading to our lives is reading's basic purpose which must be recognized by children. Providing young learners with purpos of reading will increase their compliance with doing the reading homework (Kucer, 2014).

Kotaman (2013) pointed out that reading is related to the learners' success in the early years of school since it is a key for all other learning fields such as writing, math, science, or social studies. Furthermore, he stated it is the parents' duty to integrate reading into their children's daily life habits (e.g., associating the details of a story to their social contexts). By this integration, children will attain cues for academic excellences and acquire prolific experiences such as being initiative and motivated to gain more knowledge. Parents can facilitate the development of their children's language skills such speaking and writing through the improvement of reading. To improve reading skills, parents can reinforce their children's positive attitudes towards reading (Kotaman, 2013). These attitudes can be used as future indicators for the children's successful accomplishments in school (Kotaman, 2013). 


\section{Literature Review}

\subsection{Compliance and Homework}

Compliance is rated as one of most the problematic issues in children's behaviors. Jenson, Rhode, and Neville (2010) described non-compliance as a behavior in which the child exhibits refusal for complying with the adults' requests. Ignorance, pretending not to hear or direct arguing are the prominent features of incompliance (Jenson, et al., 2010). Research and literature demonstrated the importance of homework in students' academic success and progression. In addition, these educational domains highlight the significant role of homework in promoting higher levels of learning. Compliance with doing the school homework, especially reading improves students' learning and ameliorates their knowledge in the educational area they have studied and tackled. Axelrod and Zank (2012) highlighted the positive influence of compliance with school work on students' academic performance. Accordingly, educators have to choose the most effective methods to increase their students' compliance with doing the required tasks such as home assignment. Adopting verbal disapproval or punishment may solve problem of homework incompletion, but these methods will not be exemplary ways to improve students' compliance (Axelrod \& Zank). There are several factors that impact students' desires for completing their homework. According to Tompkins (2002), students' compliance in doing homework is basically determined by several aspects such as explicit meaning and reason for doing homework and clear procedures and descriptions of the homework. Giving descriptive directions for doing the homework explains to the child the requirements of that work (Jenson, et al., 2010).

Other aspects that impact students' compliance with doing homework involve: students' abilities for doing homework, and the teachers' ways for reviewing and giving feedback (Tompkins, 2002; Margolis \& McCabe, 1997). According to Tompkins (2002), the teachers' attitudes in reviewing child's homework impact child's product of homework. These attitudes could be whether the teacher was enthusiastic, supportive or curious in student's performance. Children know their teachers' attitudes in reviewing their homework; therefore, such attitudes will influence their products (Tompkins, 2002). Positive attitudes in reviewing homework accelerate student's compliance with doing homework which leads in improving his learning levels.

\subsubsection{Reasons of incompliance with doing homework}

Homework plays a major role in increasing students' learning in any academic area. Reading homework improves the reading levels of all students, specifically, students who struggle in reading. Incompliance with doing school assignments or homework can be also exhibited at home. Some non-compliant children may refuse to complete their homework for several reasons. Bryan and Burstein (2004) discussed the main reasons attributed for incompliance with homework completion. These reasons included: lack of interests, poor skills by which students cannot meet the standards of homework completion, or the way of presenting the assigned readings which make the reading homework boring, difficult or non-attractive (Bryan \& Burstein). While Margolis and McCabe (1997) state homework is sometimes higher than students' skill levels, accordingly they refuse to do it, or they do it inadequately. 
The purpose of homework should be clear for students. The ultimate meaning of homework is represented by its purpose. If the purpose of homework is explicit for students, they will consider the assignment as a meaningful activity in which they explore and improve their knowledge. Therefore, when homework is meaningful to students, their compliance with doing it will relatively increase (Tompkins, 2002). A meaningful homework is work that focuses on learning domains which students are experiencing (Tompkins).

Other children predict their failure in these reading tasks. They may predict that they will be punished for their inadequate efforts in such reading assignments, and thus they will not read (Margolis \& McCabe, 1997). Students' predictions of the consequences of their performances in doing homework are basically derived from their prior experiences in doing these assignments. According to Gaynor, Lawrence and Nelson -Gray (2006), poor understanding of homework may cause negative experiences for students with such assignments. These negative experiences of students' homework completion increase the likelihood of homework avoidance. These experiences may involve punishment or negative reinforcement (Gaynor et al., 2006). Moreover, students may feel negatively regarding their performance in these assignments, thus they avoid doing homework at all (Leahy, 2002).

\subsubsection{Benefits of homework}

Benefits of homework are demonstrated when it is assigned to meet students' needs and to improve their levels in an educational field. Margolis and McCabe (1997) claim that reading homework is a tool for helping students to increase their learning levels, and develop their reading skills. Feedback that includes the purposes of a reading homework and how to improve the current levels is essential in developing the student's reading skill. When students realize the purposes of their homework, how it is related to their academic levels and the benefits of reading in their lives, their compliances' levels for doing the reading homework will significantly increase (Margolis \& McCabe).

\subsection{Strategies of Homework Compliance}

Tompkins (2002) proposed several effective strategies for increasing students' compliance with homework completion. One of these strategies is assigning homework that corresponds with students' abilities and capabilities. Using students' abilities in meeting homework requirements increase their compliance in doing these assignments. Bryan and Burstein (2004) suggested other strategies that can be adopted to accelerate students' compliance with doing homework. These strategies included engagement of parents' role in homework process.

\subsubsection{Parents' role in reading homework}

Young learners need assistance in doing their reading homework. Children who struggle in reading need such assistance because it will improve their reading skills. According to Bailey, Silvern, Brabham and Ross (2004), when parents lead their children in their homework, they are affecting their children's academic performance, helping their children to create the sense of independence and responsibility for the work and support the social interaction at home. When parents assist their children in their reading homework by leading them, they are accelerating their children's inferences from these readings. These children will significantly 
comprehend and infer from these texts more than those children who do not have that assistance at home (Bailey et al., 2004). Parents' support in reading assignments facilitates and promotes their children's learning (Bailey et al., 2004).

\subsubsection{Homework incentives}

Margolis and McCabe (1997) identified several incentives which encourage students to do reading homework. One of these incentives is students' interests. Students' interests in type of homework they are given increase their compliance. They will explore and enrich their knowledge about that homework content since it creates an area of interest for them. Reinforced behaviors are another incentive to encourage students to do the homework. When a behavior is directly rewarded, in other words positively reinforced, students' compliance in completing homework will accelerate because each time they do the homework, they will be rewarded. Margolis and McCabe added that the type of reinforcement should be equivalent to students' adequate reading effort, since reinforcements increase students' desire to read and create a supportive atmosphere to do the reading homework successfully. By reinforcements, homework will be an interesting activity rather than a burden, and students' efforts will be appreciated (Margolis \& McCabe).

\subsection{IPad's Apps in Education}

The emergence of technology has ameliorated various fields in education. Technological applications are being adopted by several schools to facilitate students' learning. Teachers are using such products to pave the way for more effective teaching practices. Parents may also utilize these technological applications to increase their children's learning levels (source?). Compliance with homework completion increase students' success in their academic work. Accordingly, homework could be presented in new methods for accelerating students' compliance with this school task (Bryan \& Burstein, 2004). One potential tool is the iPad. According to McClanahan, Williams, Kennedy and Tate (2012), iPads are the most prevalent devices of information and communication in education due to their efficacy in the teaching and learning processes. These authors claimed various school districts used the iPads to fulfill the students' learning needs. In addition, iPads were used by these schools to achieve several educational targets such as effective instruction that mimes the technological atmosphere where students live today (McClanahan et al., 2012). The interactive applications of iPads create innovative learning contexts for students to learn reading or writing. McClanahan et al. (2012) indicated learning how to use the iPad is easy and students can master this usage for independent use. Neely, Rispoli, Camargo, Davis and Boles (2013) discussed the unequivocal, prominent effect of the iPads on the student's behavior. Students are more involved in the instruction when iPads are used (Neely et al., 2013).

\subsubsection{Compliance and iPads}

Students' developments in all aspects of learning are being sought by educators and parents. Therefore, iPads are used for developing students' learning in all fields. Murray and Olcese (2011) stated that iPads are multi-function tools. Due to iPads' various options, they are used by many teachers to increase students' involvement in the learning process. Research 
indicates the efficiency of iPads as reinforcement tools which impacts several learning skills such as young learners' reading. Kay (2012) stated that touch screen devices such as iPads can be effective reinforcers to reduce challenging behaviors such as school work avoidance or increase positive desired behaviors such as compliance with homework. She indicated one advantage of iPads' apps is that these applications are available for children anytime and anywhere. Children can choose their preferred apps on their own because of the ease of iPad's usage.

Hutchison, Beschorner and Schmidt -Crawford (2012) stated the iPads' applications and how they present effective reading texts which can be used in literacy instruction and to improving reading problems of students. IPads options such as reading apps or ebooks provide interactive environment for ameliorating reading. EBooks or electronic pictured stories in iPads enhance students' reading because they are supported with interactive audiovisual texts.

Digital reading devices such as iPads encourage students to read since these devices have various options. These options include: creating story books with multiple multimedia applications such as visual texts or pictures with audio or video illustrations. Such options enhance the books and encourage students to perform reading practices in an attractive method (Larson, 2010). In this way we can increase students' compliance in doing the homework and at the same time encourage them to create their own stories, in their preferable format. Providing opportunities for children to create their own story books increase their compliance with the reading homework. In addition, by digital reading devices, we establish effective connection between children and reading texts (Larson, 2010).

Providing students with opportunities to experience reading with creative ways increases their interests to read, and therefore, they will be compliant with reading homework. According to Saine (2012), iPads reading or creating book apps stimulates students' creative thinking, and encourages them to discover more about reading texts through these apps. This could be an efficient tool for increasing students' compliance with homework completion. In these creative apps, children can create their own books and train on the internet usage and gathering information skills. These effective skills could be all learned with teachers or parents' scaffolding (Saine, 2012). Reading or creating story books would be effective tools for increasing students' compliance with doing homework, especially if that homework was reading. Accordingly, the purpose of this paper was to demonstrate the importance of compliance with reading homework for students whose English is their second language. In addition, this paper showcased how interactive reading books promote compliance with homework completion.

\section{Methodology}

\subsection{Participant and Setting}

The research's subject was a seven year old elementary Caucasian boy in the first grade whose English is not his first language. After administering several language tests, he was labeled as an English language learner. He had 72 minutes of English at school daily. In 
addition, he had been assigned to a Reading Recovery intervention program because he was struggling in reading. According to Bufalino, Wang, Gomez-Bellenge and Zalud (2010), Reading Recovery is an effective early one-on-one intervention which helps in promoting first grade students' reading. Although these resources were available for the participant, he continued struggling in reading. When the researcher talked with his both English as a Second Language and Reading Recovery teachers, they stated that the participant needed extra reading assignments at home every day to ameliorate his reading. Therefore, his Reading Recovery teacher assigned for him daily readings. The participant had to read a selection of two to five books from Reading Recovery every day at home.

The problem with this subject was he exhibited incompliance behavior when it came the time for doing the reading homework every evening. The subject cried and yelled refusing to read. In other times, he escaped and went to bed without doing the homework. These instances of avoidance lasted for several minutes. According to Jenson, et al. (2010), wait time for the child to comply with a request elapses between three to five seconds. The participant exceeded this period of time by more than 15 minutes before doing the reading homework.

The participant lived in a middle class family, and his both parents were educated. His mother was a $\mathrm{PhD}$ student in special education, and his father was a computer technician. He lived in middle class family, and he had an iPad. The participant spent most of his leisure times playing with his iPad apps or watching different cartoon clips. Therefore, the researcher investigated the influence of this preferable device for the participant in increasing his compliance with doing the reading homework. Unfortunately, the stories of the collection used by his Reading Recovery teacher are not available online. Therefore, the researcher created a collection of electronic Reading Recovery stories using the app (Book Creator for $\mathrm{iPad})$ as the intervention for increasing the participant's compliance with doing the homework.

The study took place at the participant's house because it was the place where he usually does his other homework assignments. Specifically, the study was carried out at his mother's office in order not to be distracted by his younger brother or their toys in their bedroom. The participant was asked to read all his reading books assigned by his Reading Recovery teacher using the iPad.

\subsection{Operational Definition}

The target behavior in this study was: complying with the reading homework by reading all the assigned readings without any instances of avoidance or incompliance including: yelling, crying, screaming, escaping, arguing or ignoring. This compliance would be measured after the first request (prompt), with no latency time in minutes. The behavior excluded asking questions for clarifying the homework.

\subsection{Research Questions}

The study investigated the following questions:

1. What was the effect of using the iPad app (Book Creator for iPads) on the participant's 
compliance in doing his reading homework?

2. How did Book Creator for iPads app increase the participant's interest in doing the reading homework? Is this a social validity question?

\subsection{Behavioral Measure}

The target behavior was assessed by using latency. Latency is appropriate for measuring the period of time the participant takes before complying with a request (Kazdin, 2011). Latency was used to measure the time the child spent before doing the reading homework after the first request. Latency was chosen since the participant took several minutes before doing the homework. This time of latency is mostly spent in several ways of avoidance of reading homework. These ways included: yelling, crying, ignoring, screaming or arguing before doing the homework. According to Kazdin (2011), latency measures the time the subject spends before responding to a prompt. Therefore, latency was the appropriate behavioral measurement to assess the time the participant takes before complying with doing the homework.

\subsection{Dependent Variable}

The goal of the study is to decrease the time the participant took before beginning his reading homework. Accordingly, the dependent variable of the study was compliance with doing the reading homework. Latency was used for measuring the actual time the participant took before doing the homework. The reduction of that time was representative of the child's compliance. In other words, the less time the child took before doing his reading homework, the more compliant he would be. It is hypothesized completing the reading homework daily will improve the participant's reading. From this it is noted that completing reading homework is academically and socially important. The observers measured the time the participant spent before doing the reading homework. This time was measured from the first request till the participant's start point or on-task status. The observers used stopwatches to calculate the time of latency. According to Kazdin (2011), stopwatches facilitate the process of counting the time of latency. The observers used latency measure forms to order their observations with actual start and stop times. The observers independently observed the child's performance after prompting. In addition, they calculated the percentages of time the child was off -task in the phases of the study, and recorded these percentages on their forms.

\subsection{Independent Variable}

The independent variable is the iPads app (Book Creator for iPads). This intervention was selected by the researcher for several reasons. The main reason was the participant's interest in iPad and its apps. In addition, since the participant had an iPad and he knew very well how to use it, Book Creator for iPads was an effective tool to increase the student's compliance with doing homework. The options that this app provides such as creating texts, adding audio or visual additions to the texts created interactive reading environment for the child. This environment increased his interest and compliance with doing the reading homework. The usage of Book Creator for iPads is simple. Thus, it was easily used by the participant. 
As stated earlier, because the collection of Reading Recovery was not available online, the researcher created electronic books for the Reading Recovery's collection using Book Creator for iPads app. The researcher contacted the participant's Reading Recovery teacher asking her for the assigned books. The collection used for Reading Recovery homework was Just Right. The teacher provided the researcher with a list of all the (Just Right) collection's books. The researcher purchased 27 books of this collection, and created them in electronic book form to use during the intervention sessions. Because Book Creator for iPads provides flexibility to create stories with several features, the researcher could easily create the electronic books of the assigned collection. The flexibility of Book Creator is demonstrated in its options of using online or captured pictures, audio or video clips and other multimodal options. In the intervention phases and before implementing this app, the researcher explained to the participant that he had to read his assigned readings by electronic books using the iPad. During the implementation of this intervention, the researcher prepared the setting with suitable furniture such as table and two chairs for the participant and observer. The child was asked to do the homework, after returning back from school, having dinner and taking a rest (10 - 15 minutes). Fifteen minutes were the time assigned for each reading session in all phases.

\subsection{Reliability of the Data}

Before collecting data, the reliability checker was trained for collecting data. The IRIS Center resources were effective references for the reliability checker before engaging practically in the process of data collection. Several Behavior modules were assigned for the reliability checker to grasp the concept of behavioral compliance and how to measure it with latency. Because the reliability checker was not an educator, the researcher assigned him several readings about behavioral measurements and their usage. The reliability checker participated in a one hour training sessions daily for 15 days. In these sessions, the reliability checker and the first observer practiced collecting data by measuring latency of compliance from several videos. The reliability checker and the first observer kept using these training sessions until they had the same percentage of time off-task, and then they started collecting the actual data. Furthermore, the interrater reliability was scored on the time the participant spent before complying with doing the reading homework.

\subsection{Reliability of Independent Variable}

For checking the reliability of the independent variable, a procedural reliability check list was used. This checklist included several procedures that were followed in the implementation of the intervention. These procedures included: asking the child to go to the office room, open his iPad on the Book Creator app and select the assigned book. A stop watch was used to record the time from the first prompt until the child began reading the book on the iPad. This list checked the fidelity of the intervention's implementation. These checklists for fidelity were used during each session by the observers. Observers checked each procedure as presented or not. Such fidelity checklists demonstrated the precise procedures of the intervention's implementation. Fidelity is highly desired in researches to ensure the accuracy of implementing the intervention (Horner et al., 2005). 


\subsection{Experimental Design}

A withdrawal design was used to evaluate the effectiveness of iPads apps on the compliance of completing reading homework. One of the basic features of this design is that it goes into phases in which the intervention is implemented and withdrawn (Kazdin, 2011). In such manipulation of the intervention, the effect of this intervention on the target behavior is explicitly noticed. Furthermore, it highlights the functional relationship between the intervention and behavior (Kazdin, 2011). This design goes in the format of ABAB in which A refers to the baseline, $\mathrm{B}$ refers to intervention, the second $\mathrm{A}$ and $\mathrm{B}$ are replications of the baseline and intervention phases. According to Kazdin (2011), in baseline phase the behavior is observed before implementing the intervention. In this phase, we can see the current performance and predict the performance without intervention. The second phase which is the intervention phase demonstrates whether the behavior is affected by the intervention. The intervention phase predicts the behavior if the same conditions of the intervention's implementation do not change (Kazdin, 2011).

The rationale for using the withdrawal design was to check that the variations of behavior are due to the intervention. According to Kazdin (2011), replication of baseline and intervention in $\mathrm{ABAB}$ tests our prediction of the behavior with or without the conditions of implementing intervention. In addition, the second implementation of the treatment demonstrates that the change of the behavior was not caused by threats of internal validity such as maturation, history or external validity such as interaction effects of interventions (Kazdin, 2011). By implementing and withdrawing the intervention, the researcher could control these threats to the validity, and attribute the change in the target behavior to the treatment used in the study rather than anything else (Kazdin, 2011). The logic of the phases' order in this design enables researchers deduce inferences about the effectiveness of the intervention and its effect in changing the target behavior (Kazdin, 2011). Due to these advantages of the withdrawal design, it was used in this study. Another rationale for using this design was the applicability of withdrawing the intervention to see the change on the behavior. In this case, we could withdraw the intervention since the child had the paper versions of homework books. Therefore, the participant was not preventing totally from the readings which would be unethical manner with a child learning reading in a second language. The issue of ethics should be considered before selecting the design (Kazdin, 2011).

The intervention was implemented after collecting five data points because "baseline typically requires multiple data points (five or more)" (Horner et al., 2005, 168). In the baseline phase, the observers calculated the amount of time that elapsed after prompting the participant to begin his reading homework. The observers used a stopwatch to calculate the latency time of the child before complying. Because it was a withdrawal design, the intervention was introduced after the baseline phase. Then, it was withdrawn to see how the participant performed. After this second baseline, the intervention was introduced again to check the impact of the iPads' apps on the child's homework completion. By this phase, the app's influence was tested and whether it caused that change in the student's performance rather than any other factors. 


\section{Results}

Results demonstrated high compliance of the participant with doing homework. That was represented in the latency times during the intervention phases. Figure 1 demonstrates the phases of implementing and withdrawing the Book Creator app. The figure also demonstrates the first baseline data. It is noted that there was a functional relationship between the intervention and compliance (behavior). It is clear how the latency time was decelerating when the intervention was implemented. You also need to discuss the functional relationship.

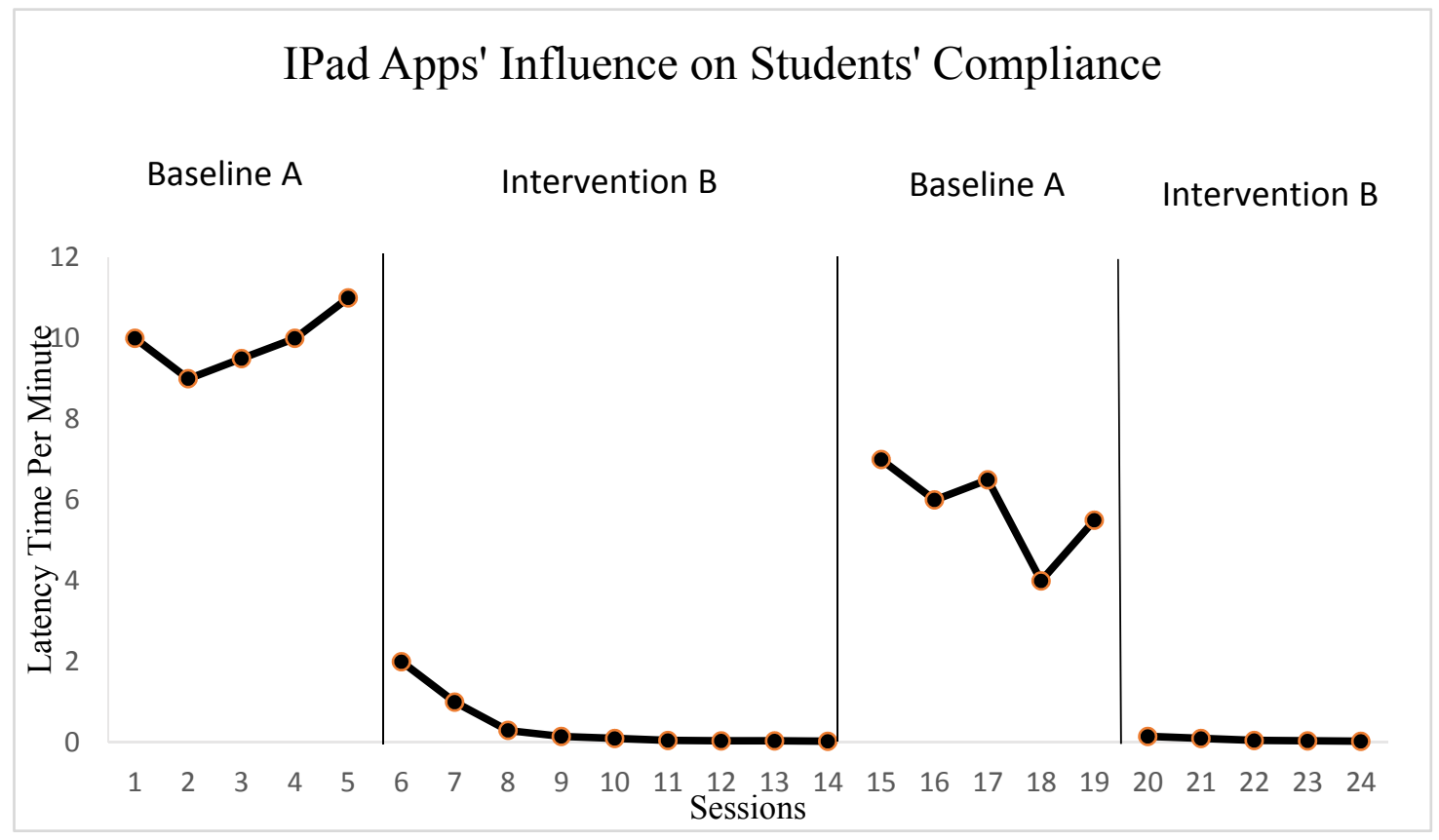

Note. Some of latency times in intervention phases were in seconds. The latency times of seconds ranged between 15 to 3 seconds. This graph displays the latency time per minutes.

Figure 1. Results of implementing and withdrawing the electronic books in Book Creator app Although the graph demonstrates that some data points' latency times were zero, the time elapsed between the some prompts and complying with the request was calculated in seconds (between 15 and 3 seconds). Latency was used to measure the target behavior (compliance with doing homework) for twenty four sessions. Ten sessions were for the two baseline phases. During first baseline the latency time ranged from 9 to 11 minutes. The latency times in the first intervention phase ranged from 0 to 2 minutes. The third phase which was the second baseline, the latency time increased again decreasing the level of compliance because of withdrawing the intervention. The latency times ranged from 4 to 7 minutes. Then the last phase, the deceleration of the latency times that ranged from 15 to 3 seconds was noticed, in other words they were all zero minutes. The two observers had the same percentages of time off- task during the four phases. The percentages were calculated by dividing the time of latency by the time of each reading session (15 minutes) and the total was multiplied by 100 . Table 1 displays the percentages of off-task behavior in the four phases for both observers. 


\section{Macrothink}

Table 1. Percentages of Times off - Task in All Phases

\begin{tabular}{lllll}
\hline Phase/session & Baseline 1 & Intervention 1 & Baseline 2 & Intervention 2 \\
\hline $\mathbf{1}$ & $66 \%$ & $13 \%$ & $46 \%$ & $1 \%$ \\
$\mathbf{2}$ & $60 \%$ & $6 \%$ & $40 \%$ & $.66 \%$ \\
$\mathbf{3}$ & $63 \%$ & $2 \%$ & $43 \%$ & $.33 \%$ \\
$\mathbf{4}$ & $66 \%$ & $1 \%$ & $26 \%$ & $.26 \%$ \\
$\mathbf{5}$ & $73 \%$ & $.66 \%$ & $36 \%$ & $.2 \%$ \\
$\mathbf{6}$ & & $.33 \%$ & & \\
$\mathbf{7}$ & $.26 \%$ & & \\
$\mathbf{8}$ & $.26 \%$ & & \\
$\mathbf{9}$ & $.2 \%$ & & \\
\hline
\end{tabular}

The visual inspection of the study demonstrated the effectiveness of the Book Creator in increasing the participant's compliance with doing the homework. Table 2 demonstrates the descriptive statistics which indicated the efficient impact of the intervention on compliance by decreasing the time of latency before doing the homework. There was a functional relationship between intervention and behavior.

Table 2. Quantitative Data of the Four Phases

\begin{tabular}{lllll}
\hline Phase/Statistics & Baseline 1 & Intervention 1 & Baseline 2 & Intervention 2 \\
\hline Mean & 9.9 & .41 & 5.8 & .074 \\
Median & 10 & .1 & 6 & .05 \\
Range & $9-11$ minutes & $\begin{array}{l}.03 \text { seconds }-2 \\
\text { minutes }\end{array}$ & $5.5-7$ minutes & $.03-.15$ seconds \\
& & $.71-.052$ & $5.5-.15$ & $.1-.04$ \\
Trend & $9.5-10.16$ & 6.97 & 5.35 & - \\
& 9 & & & 0 \\
Level & 0 & 0 & 0 & \\
Latency & & &
\end{tabular}

Note. Level for the second intervention phase was not calculated because we did not have a fifth phase.

\subsection{Social Validity}

Social validity will be enhanced when the independent variable changes the outcome, and that change is socially essential (Horner et al., 2005). The implementation of the intervention in this study impacted the dependent variable or reading homework completion. Electronic books created by Book Creator were appropriate tool for accelerating the child's compliance with reading homework. According to Horner et al. (2005), implementing a practical intervention would enrich the study's social validity. In this study iPad's Book Creator was a practical intervention since the participant has an iPad and adopts it as a tool for leisure. For social validity, the researcher asked the participant about his perspective regarding using the electronic books instead of reading them in papers. The participant explained that these versions of books are more attractive and interesting since they enabled him to navigate and explore many resources about any topics provided in the books. He could use the hyperlinks 
provided with some narrations in some books to increase his information. The participant also expressed his enthusiasm to learn how to create other stories and record his own voice to narrate these stories. The participant demonstrated that these books encouraged him to learn more about the stories by their interactive pictures and demonstrations.

\section{Discussion}

The results implied the positive impact of Book Creator for iPads on the compliance of homework completion. It is evident that Book Creator changed the non-compliant behavior into more compliant performance with doing the homework. In addition, it encouraged the participant's creative thinking of creating other stories and narrating them with his own voice. This result corresponds with what Saine (2012) inferred - that iPads encourages the children's creativity in learning. It is noted that Book Creator was effective in increasing compliance, and it would be an appropriate tool for educators to increase such behavior even in classroom settings. With Book Creator the child became more engaged in reading homework, continued smoothly to answering the discussion questions after each reading sessions and talked about his experience with these electronic and interesting books to his family and even teachers at school. Saine (2012) highlighted the significant effect of these interactive apps in involving students in core instruction. Book Creator is an appropriate tool for encouraging young learners for obtaining positive behaviors which affect their academic performances at school by making them more engaged in this environment. When children exhibited compliable behaviors, they would learn more effectively. Their learning levels will be promoted and they will demonstrate more successful efforts in school life. Homework completion is one of the key elements that lead to success in learning.

Results demonstrated the high compliance levels of the participant in doing the reading homework when Book Creator was used. Through intervention phases, the child sometimes wanted to start reading before even the assigned time of the daily homework time. From that it is deduced that the child's interest levels in complying with reading homework increased because of the iPad's usage. This could be due to the app's options in creating interactive books with audio or visual demonstrations. The hyperlinks and the images attracted the participant making him spend extra time after doing the daily readings. The time spent after the reading homework was completed included discussion and exploration of the hyperlinks of other children's resources dealing with same topics of the reading books. This result demonstrated the child's positive change regarding homework. Before the study, in addition to long latency time, the child used to read one book without agreeing to spend any additional time answering discussion questions. However, with the iPad the child spent more time reading the assigned books, discussing these stories and exploring the additional resources with the researcher's scaffolding. The time the child spent for doing the reading homework elapsed between thirty - fifty minutes. The study's results indicated the efficiency of the iPad's applications in increasing other domains beyond compliance levels. Book Creator for iPad application was an effective tool in improving the participant's compliance with reading homework, his interests in homework and related materials to this school assignment. The 
results revealed the impact of this app in increasing the participant's compliance and interests of reading homework.

\section{Recommendation and Limitation}

Future research about the usage of iPads' applications, especially, Book Creator in literacy instruction is recommended. Future investigation can be conducted in the domain of the impact of educational iPads applications in decreasing other behavioral problems such as anxiety or depression that can be noticed in many school students. Like Book Creator, several iPads applications demonstrated high efficiency in improving literal levels such as writing or reading (Hutchison, et al., 2012). It would be beneficial for educators and educational researchers to explore other iPads applications that can be effective not only in literal instruction, but also in social engagement in learning.

The present study and its implications involved a number of limitations. One of these limitations is relatively the short period of time given for the second intervention phase. The results indicated that this phase was conducted during only five sessions. That was due to the participant's engagement in other school work. Another limitation is demonstrated in the setting. Although the setting was at the participant mother's office at the participant's house, many times the participant was off-task due to some distractions. The participant sometimes was distracted with some incidents in his house including: his father's arrival or departure from the house or his brother's requests for playing with him. It is noticed that the participant was one of the children who were quickly distracted, although he was not diagnosed as having any attention deficits. Accordingly, it would be better if the researcher conducted the study in another free of distraction setting such as the school library or at the researcher's office.

\section{References}

Axelrod, M. I., \& Zank, A. J. (2012). Increasing classroom compliance: Using a high-probability command sequence with noncompliant students. Journal of Behavioral Education, 21(2), 119-133. http://dx.doi.org/10.1007/s/0864-011-9175-6

Bailey, L. B., Silvern, S. B., Brabham, E., \& Ross, M. (2004). The effects of interactive reading homework and parent involvement on children's inference responses. Early Childhood Education Journal, 32(3), 173-178.

Bryan, T., \& Burstein, K. (2004). Improving homework completion and academic performance: Lessons from special education. Theory into Practice, 43(3), 213-219.

Bufalino, J., Wang, C., Gomez-Bellenge, F. X., \& Zalud, G. (2010). What's possible for first - grade at risk literacy learners receiving early intervention services? Literacy Teaching and Learning, $15(1 \& 2), 1-15$.

Buyuktaskapu, S. (2012). Effects of family supported pre-reading training program given to 
children in preschool education period on reading success in primary school. Educational Sciences: Theory \& Practice, 12(1), 309-316.

Gaynor, S. T., Lawrence, P. S., \& Nelson-Gray, R. O. (2006). Measuring homework compliance in cognitive-behavioral therapy for adolescent depression: Review preliminary findings, and implications for theory and practice. Behavior Modification, 30(5), 647-672. http://dx.doi.org/10.1177/0145445504272979

Horner, R. H., Carr, E. G., Halle, J., McGee, G., Odom, S., \& Wolery, M. (2005). The use of single-subject research to identify evidence-based practice in special education. Exceptional Children, 71(2), 165-179.

Hutchison, A., Beschorner, B., \& Schmidt-Crawford, D. (2012). Exploring the use of the iPad for literacy learning. The Reading Teacher, 66(1), 15-23.

Jenson, W. R., Rhode, G., \& Neville, M. H. (2010). The tough kid: Parent book. Oregon: Pacific Northwest Publishing.

Justice, L. M., \& Sofka, A. E. (2010). Engaging children with print: Building early literacy skills through quality read-alouds. NY: The Guilford Press.

Kay, S. (2012). Can touch screen tablets help children with autism? Exceptional Parent, 42(11), 38-38.

Kazdin, A. E. (2011). Single-case research designs: Methods for clinical and applied settings. NY: Oxford University Press.

Kotaman, H. (2013). Impacts of dialogical storybook reading on young children's reading attitudes and vocabulary development. Reading Improvement, 45(2), 199-204.

Kucer, S. B. (2014). What retellings can tell us about the nature of reading comprehension in school children. Australian Journal of Language and Literacy, 37(1), 31-44.

Larson, L. C. (2010). Digital readers: The next chapter in e-book reading and response. The Reading Teacher, 64(1), 15-22.

Leahy, R. L. (2002). Improving homework compliance in the treatment of generalized anxiety disorder. Journal of Clinical Psychology, 58(5), 499-511.

Margolis, H., \& McCabe, P. P. (1997). Homework challenges for students with reading and writing problems: Suggestions for effective practices. Journal of Educational and Psychological Consultation, 8(1), 41-74.

McClanahan, B., Williams, K., Kennedy, E., Tate, O., \& Tate, S. (2012). A breakthrough for Josh: How use of an iPad facilitated reading improvement. TechTrends, 56(3), 1-8.

Murray, O. T., \& Olcese, N. R. (2011). Teaching and learning with iPads, reading or not? TechTrends, 55(6), 42-48.

Neely, L., Rispoli, M., Camargo, S., Davis, H., \& Boles, M. (2013). The effect of instructional use of an iPad on challenging behavior and academic engagement for two 
students with autism. Research in Autism Spectrum Disorders, 7(4), 509-516.

Saine, P. (2012). Computers in classroom: IPods, iPads, and the smart board: Transforming literacy instruction and student learning. New England Reading Association Journal, 47(2), 74-79.

Tompkins, M. A. (2002). Guidelines for enhancing homework compliance. Journal of Clinical Psychology, 58(5), 565-576.

Wanzek, J., Al Otaiba, S. A., \& Petscher, Y. (2014). Oral reading fluency development for children with emotional disturbance or learning disabilities. Council for Exceptional Children, 80(2), 187-204.

\section{Copyright Disclaimer}

Copyright for this article is retained by the author(s), with first publication rights granted to the journal.

This is an open-access article distributed under the terms and conditions of the Creative Commons Attribution license (http://creativecommons.org/licenses/by/3.0/). 